\title{
ESPAÑA, 18 DE JULIO DE 1936. GUERRA CIVIL Y VERSOS REPUBLICANOS
}

\author{
Maria Luisa Rodríguez Peñaranda* \\ Alberto Castrillón ${ }^{* *}$
}

\begin{abstract}
La muerte de cualquier hombre me disminuye porque estoy ligado a la humanidad, por eso nunca preguntes por quién doblan las campanas: doblan por ti. John Donne, 1624, 109
\end{abstract}

Fue en España donde mi generación aprendió que uno puede tener razón y ser derrotado, golpeado, que la fuerza puede destruir el alma, y que a veces el coraje no obtiene recompensa. Albert Camus, 1944

\begin{abstract}
$\mathrm{E}$ 118 de julio de 2016 se conmemoran 80 años del fallido golpe de Estado al mando de Francisco Franco, fracaso que provocó la Guerra Civil Española (1936-1939). Apenas cinco meses después de llegar a su cruento final comenzó la Segunda Guerra Mundial. Si la guerra española se hubiese prolongado unos meses más, como deseaban los republicanos, se habría superpuesto a la guerra mundial, y otra podría haber sido la suerte de la breve Segunda República Española.

E1 4 de enero de 1939, cuatro meses antes de la victoria del franquismo, el presidente Franklin Delano Roosevelt reconoció que la política exterior estadounidense -igual que la de Francia e Inglaterra- de abandonar a la República a su suerte, y dejarla en manos del fascismo alemán e italiano, había sido un grave error. Ese día, Roosevelt advirtió

* Doctora en Derecho Constitucional, profesora asociada de la Universidad Nacional de Colombia, Bogotá, Colombia, [mlrodriguez@unal.edu.co].

** Maestría en Desarrollo Económico, profesor de la Universidad Externado de Colombia, Bogotá, Colombia, [jracastrillon@yahoo.com]. Fecha de recepción: 10 de mayo de 2016, fecha de aceptación: 12 de mayo de 2016. Sugerencia de citación: Rodríguez P., M. L. y A. Castrillón. "España, 18 de julio de 1936. Guerra civil y versos republicanos", Revista de Economía Institucional 18, 34, 2016, pp. 331-337. DOI: http://dx.doi.org/10.18601/01245996.v18n34.19
\end{abstract}


al Congreso de su país que la política de neutralidad había ayudado al agresor y abandonado a la víctima, un acto miope que perjudicaba a su mismo país: "el instinto de autoprotección tendría que advertirnos de que no deberíamos dejar que sucediera nunca más" (Bosch, 2012, 210). Barcelona cayó en manos de los nacionalistas veintitrés 23 días después de su alocución, y Roosevelt reconoció que de no ser por el embargo de armas a la República, "la España leal podría haber luchado por su vida y por algunas de las nuestras también, como los acontecimientos demostrarán con mucha probabilidad" (ibíd., 215). Roosevelt no se equivocó: más de 400.000 estadounidenses murieron en la guerra mundial que empezó apenas terminó la guerra en España.

Pocas guerras han tenido las repercusiones que tuvo la de España: miles de libros, cientos de películas y documentales tratan de ella. Los nombres de Ernest Hemingway, George Orwell, John dos Passos, Willy Brandt, Georges Bernanos, Arthur Koestler, Octavio Paz, André Malraux, Pablo Neruda, Antoine de Saint-Exupéry, Albert Hirschman, Artur London y otros más, para solo mencionar extranjeros, quedaron vinculados para siempre a esta guerra. El primer epígrafe de este escrito hace referencia al título de la novela de Ernest Hemingway, Por quién doblan las campanas, escritor estadounidense galardonado en 1954 con el premio Nobel de literatura, quien era corresponsal de guerra y simpatizaba con la causa republicana.

Casi 50.000 voluntarios, provenientes de 54 países, formaron las Brigadas Internacionales que participaron en la guerra civil al lado de la República y contra los militares sublevados ante el gobierno legítimo surgido en las elecciones de 1936. La mayoría de los brigadistas eran jóvenes de distinta condición social, tenían distintas ideologías, religiones y partidos, incluso muchos sin partido. Compartían la idea de detener el fascismo, de que luchar contra él era luchar por su propio país. En carta de un obrero y brigadista inglés enviada a su hija, este le explica sus razones:

Quiero explicarte por qué dejé Inglaterra. Te habrás enterado de la guerra que hay aquí. De todos los países del mundo, gente obrera como yo ha venido a España a parar al fascismo. Así, aunque estoy a miles de millas de ti, estoy luchando para protegerte a ti y a todos los niños de Inglaterra, así como a la gente de todo el mundo (K. W. Watkins, citado por Casanova, 2013).

Antoni Domènech recuerda que "ningún otro acontecimiento ha conmovido tanto ni tan perdurablemente a la opinión pública democrática internacional del siglo XX como esa tenaz resistencia del pueblo español" (2004, 448). Miles de hombres y mujeres asumieron como suya la causa de la República, causa que murió defendiéndose contra los insurrectos apoyados por las tropas de Mussolini y Hitler. 
Las Brigadas Internacionales empezaron a ser retiradas de suelo español el 23 de septiembre de 1938, con la vana esperanza de que esa medida modificara la posición del Comité de no Intervención -o Comité de Londres-, lo que no ocurrió. Los gobiernos fascistas siguieron enviando soldados y pertrechos de guerra, como habían hecho desde el inicio del intento de golpe de Estado. Los gobiernos de Francia, Inglaterra y Estados Unidos asistieron impasibles a la primera victoria del fascismo.

Militares felones, fascistas de torva laya, banqueros y hombres de negocios -como los March y los Ferro-, terratenientes despiadados y eclesiásticos imitadores de Jozet Tiso y Theodor Innitzer, el cardenal de Viena que recibió con alborozo la llegada de Hitler y del Anschluss de 1938, se coaligaron para destruir la República, desde su comienzo; e incluso antes, según ha demostrado la investigación histórica (Viñas, 2012). La Iglesia católica santificó el levantamiento militar como una cruzada, con la estrecha colaboración del Vaticano: declaró que no era una guerra civil sino una guerra por Dios, por la Iglesia, por el mundo y contra el mal, representado por la República. José María Pemán (1897-1981) escritor católico ultramontano lo aclamó con prosa inquisitorial: "E1 humo del incienso y el humo del cañón, que sube hasta las plantas de Dios, son una misma voluntad vertical de afirmar una fe y sobre ella salvar un mundo y restaurar una civilización" (citado en Raguer, 2001, 9). Una excepción fue Francesc d'Asis Vidal, arzobispo de Tarragona, quien se negó a firmar la carta colectiva de los obispos españoles con motivo de la guerra en España.

\section{LOS POETAS}

Recordemos algunos versos de poetas que apoyaron la República Española e incluso dieron la vida a causa de ella, como Miguel Hernández (1910-1942) o García Lorca (1898-1936). La selección es caprichosa, pues son cientos los poetas republicanos que se podrían recordar. Existen excelentes antologías de esta poesía.

Prolegómenos: en 1917 Antonio Machado parecía avizorar la tragedia:

$$
\begin{aligned}
& \text { Ya hay un español que quiere } \\
& \text { vivir y a vivir empieza, } \\
& \text { entre una España que muere } \\
& \text { y otra España que bosteza. } \\
& \text { Españolito que vienes } \\
& \text { al mundo, te guarde Dios. } \\
& \text { Una de las dos Españas } \\
& \text { ha de helarte el corazón. }
\end{aligned}
$$


Primeras batallas: la revolución asturiana de 1934 fue cantada por Pedro Garfias en 1941:

$$
\begin{aligned}
& \text { Asturias verde de montes } \\
& \text { y negra de minerales... } \\
& \text { Dos veces, dos, has tenido } \\
& \text { ocasión para jugarte } \\
& \text { la vida en una partida, } \\
& \text { y la dos te la jugaste. } \\
& \text { ¿uién derribará este árbol } \\
& \text { de Asturias, ya sin ramaje, } \\
& \text { desnudo, seco, clavado } \\
& \text { con su raíz entrañable } \\
& \text { que corre por toda España } \\
& \text { crispándonos de coraje? } \\
& \text { Mirad, obreros del mundo } \\
& \text { su silueta recortarse } \\
& \text { contra ese cielo impasible } \\
& \text { vertical, inquebrantable, } \\
& \text { firme sobre roca firme, } \\
& \text { herida viva su carne. }
\end{aligned}
$$

La muerte del amigo: Antonio Machado (1875-1939), amigo de Federico García Lorca desde 1916, compuso El crimen fue en Granada meses después del asesinato del poeta granadino por los fascistas:

$$
\begin{gathered}
\text { Se le vio, caminando entre fusiles, } \\
\text { por una calle larga, } \\
\text { salir al campo frio, } \\
\text { aún con estrellas, de la madrugada. } \\
\text { Mataron a Federico } \\
\text { cuando la luz asomaba. } \\
\text { El pelotón de verdugos } \\
\text { no osó mirarle la cara. } \\
\text { Todos cerraron los ojos; } \\
\text { rezaron: ini Dios te salva! } \\
\text { Muerto cayó Federico } \\
\text {-sangre en la frente y plomo en las entrañas- } \\
\text {... Que fue en Granada el crimen } \\
\text { sabed -ipobre Granada!-, jen su Granada!... }
\end{gathered}
$$

La guerra: Pablo Neruda, cónsul en Madrid al inicio de la guerra vivía en la Casa de las Flores, la cual sufrió daños en los primeros bombardeos a la capital española. Publicó el libro España en el corazón. En "Explico algunas cosas", poema allí incluido, canta:

$$
\begin{gathered}
\text { Os voy a contar todo lo que me pasa. } \\
\text { Yo vivia en un barrio } \\
\text { de Madrid, con campanas, } \\
\text { con relojes, con árboles. } \\
\text { Desde alli se veía } \\
\text { el rostro seco de Castilla } \\
\text { como un océano de cuero. } \\
\text { Mi casa era llamada } \\
\text { la casa de las flores, porque por todas partes }
\end{gathered}
$$




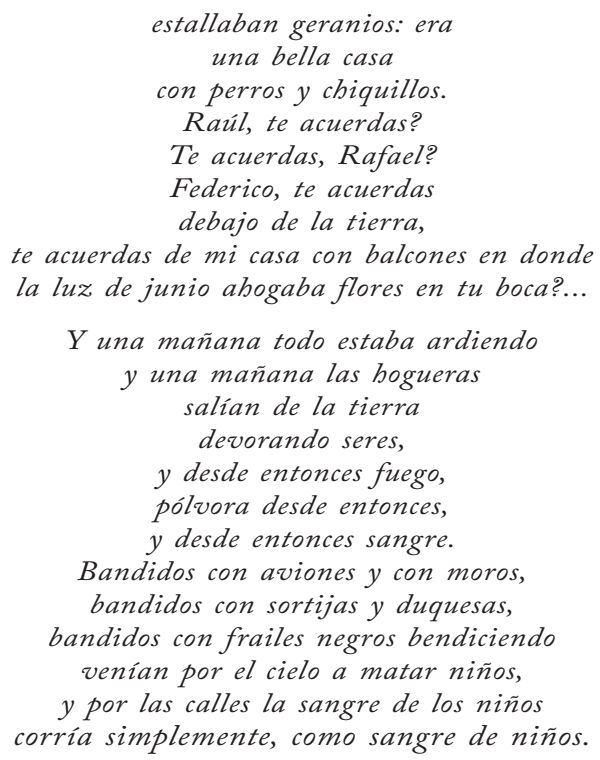

LA CÁrcel: Miguel Hernández, quien murió en las cárceles de Franco tres años después del fin de la guerra, compuso en su celda este hermoso poema en respuesta a una carta de su mujer en la que le decía que ella y su hijo pequeño solo tenían un poco de cebollas para comer:

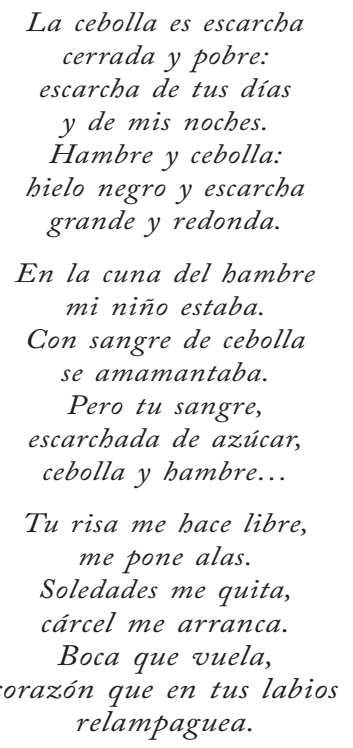

El Exilio: miles de partidarios de la República fueron al exilio, unos a América; donde fueron acogidos generosamente por México, país que apoyó a la República hasta el fin. Otros fueron a Argentina, Colom- 
bia, República Dominicana, Estados Unidos... Miles de asilados en Francia continuaron su lucha contra el fascismo en ese país, invadido y derrotado por las tropas nazis en 1940. A Rafael Alberti (1902-1999) le debemos los versos de Juan Panadero en América.

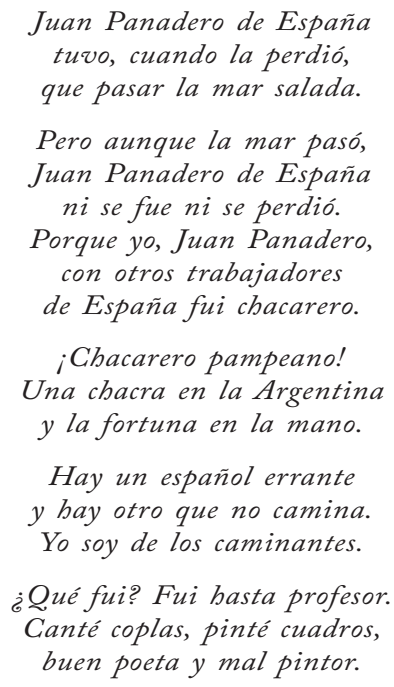

\section{EPÍLOGO}

La Guerra Civil Española aún suscita polémica, sobre todo en España, donde las heridas no acaban de restañar, como indica la discusión ocasionada por la publicación del infortunado Diccionario Biográfico Español de la Real Academia de la Historia, que afirmó entre otros exabruptos que Franco no fue un dictador. Esa tergiversación no solo acabó con el poco prestigio que le quedaba a la Academia, sino que fue obligada a rectificar. Carmen Iglesias, primera mujer en presidir la Real Academia de la Historia y quien reemplazó a Gonzalo Anes, responsable del desaguisado, afirmó: “QQue el franquismo es una dictadura? Todo el tiempo. Cuando entré en la universidad sabías que te la jugabas si te metías en política" (El País, 7 de abril de 2015).

La búsqueda de la verdad y la honestidad intelectual en el trabajo histórico son pilares no solo del trabajo intelectual, sino de la libertad y la democracia. Llamar las cosas por su nombre y desoír los cánticos que incitan a la guerra, una guerra que las sirenas perversas eludirán, es un deber de quienes creen que el estado de cosas en Colombia es inaceptable. La mentira y la impudicia no pueden ser la guía para establecer una verdadera democracia. 


\section{REFERENCIAS BIBLIOGRÁFICAS}

1. Bosch, A. Miedo a la democracia. Estados Unidos ante la Segunda República y la guerra civil española, Barcelona, Crítica, 2012.

2. Casanova, J. España partida en dos. Breve historia de la guerra civil española, Barcelona, Crítica, 2013.

3. Domènech, A. El Eclipse de la fraternidad: una revisión republicana de la tradición socialista, Barcelona, Crítica, 2004.

4. Raguer, H. La pólvora y el incienso. La Iglesia y la Guerra Civil Española (1936-1939), Barcelona, Península, 2001.

5. Trapiello, A. Las armas y las letras. Literatura y guerra civil (19361939), Barcelona, Austral, 2011.

6. Viñas, A., ed. En el combate por la historia. La República, la guerra civil, el franquismo, Barcelona, Pasado y Presente, 2012. 